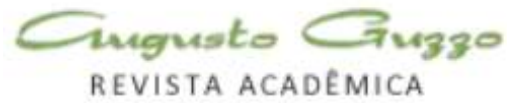

\title{
Aprendizagem Nas Organizações
}

\section{Learning In Organizations}

\author{
Cimara Apostólico
}

\begin{abstract}
Mestre em Comunicação e Semiótica. Graduada em Letras e Pedagogia. Possui Especialização em Docência do Ensino Superior e Língua Inglesa e MBA em Gestão Empresarial. Leciona na Faculdade Campos Salles nos cursos de Pedagogia e Administração. Também atua na Prefeitura de São Paulo como professora de Educação Infantil e Fundamental 1 e no Governo do Estado de São Paulo na disciplina de Língua Portuguesa e Literatura. Email professoracimara@gmail.com
\end{abstract}

\section{Resumo}

As empresas entendem o capital humano como diferencial competitivo na busca por práticas mais satisfatórias, por essa razão promovem treinamentos cujo foco principal é capacitar os indivíduos para desempenho com qualidade. Este artigo pretende discutir acerca da importância da gestão do conhecimento na aprendizagem organizacional. Para esse fim, foram feitas análises com base qualitativa analítica de caráter documental e bibliográfico. Como os indivíduos são complexos: agem e reagem de maneira diferente na apreensão das informações, são necessárias estratégias diversificadas que considerem o indivíduo, o meio e as circunstâncias, além disso, é imprescindível a realização de diagnóstico preciso e refinado por meio da experiência dos orientadores dos treinamentos. A gestão do conhecimento é o diferencial nas organizações, todavia, apesar de diversas pesquisas acerca desse assunto, ainda pode-se considerá-lo incipiente, uma vez que os estudos apenas apontam na direção do que se deve alcançar, mas cujo alvo ainda está bastante distante.

Palavras-chave: organização, indivíduos, gestão do conhecimento, treinamento.

\begin{abstract}
The companies understand the human capital as a competitive practices in the search for satisfactory ways, therefore promote training whose main focus is to empower individuals with quality performance. This article discusses about the importance of knowledge management in organizational learning. To this end, analyzes were made on the basis of qualitative analytical nature documentary and bibliographic. As individuals are complex: they act and react differently in the seizure of information, strategies are needed that consider the diverse individual, the environment and the circumstances, moreover, it is essential to carry out accurate diagnosis and refined through experience of guiding trainings. Knowledge management is the difference in organizations; however, despite several studies on this subject, we can still consider it incipient studies since only point in the direction of what must be achieved, but whose target is still quite distant.
\end{abstract}

Keywords: organization, individual, knowledge management, training. 


\section{Introdução}

As transformações ocorridas no último século mudaram sensivelmente a maneira como as empresas lidam com o capital humano, que passa a ter destaque, uma vez que os processos decisórios - que são estabelecidos por intermédio do conhecimento: tanto explícito como tácito estão intrinsecamente relacionados aos lucros das organizações. A maioria das empresas sabe que a velocidade e qualidade para o desenvolvimento de suas atividades dependem dos indivíduos. tornouse então, fundamental, que os funcionários recebam treinamento adequado para lidar com as operações de trabalho e as diversas e constantes mudanças na busca da eficiência e assertividade. Para isso disponibilizam recursos financeiros com vistas a promover melhores resultados por meio da gestão do conhecimento.

A gestão do conhecimento é um conceito bastante difundido na atualidade e isso se deve, prioritariamente, à relação entre conhecimento $\mathrm{x}$

\footnotetext{
${ }^{1} \mathrm{O}$ pensamento sistêmico se caracteriza por mudanças: das partes para o todo; dos objetos para os relacionamentos; das hierarquias para as redes; da causalidade linear para a circularidade; da estrutura para o processo; da metáfora mecânica para a metáfora do organismo vivo e outras não mecânicas; do conhecimento objetivo para o conhecimento
}

processo decisório, ou seja, quanto mais informações, mais acertadas serão as decisões. Em outras palavras; para que as operações se processem de maneira eficaz e eficiente, é fundamental uma visão sistêmica acerca das organizações, o que consequentemente promoverá visão ampliada das possibilidades envolvidas, aumentando, portanto, as condições de um processo decisório acertado.

Peter Senge (2005, pág.42) afirma que na última década houve uma revolução sistêmica ${ }^{1}$, começando na física e passando gradualmente para a biologia, penetrando nas ciências cognitivas e ciências sociais. Destaca que nossas instituições ainda são organizadas com bases mecanicistas e isso representa que ainda se passarão 50 a 100 anos antes que a revolução sistêmica se integre à nossa forma de viver.

O objetivo do presente artigo é discutir a respeito da aprendizagem organizacional, compreendendo quais elementos são facilitadores para que os colaboradores aprendam e apliquem esses conteúdos em suas atividades cotidianas.

contextual e epistêmico; da verdade para as descrições aproximadas; da quantidade para a qualidade; do controle para cooperação, influenciação e ação não violenta. (ANDRADE, A.L, 2006, pág. 43 a 48 
Para aprofundarmos um pouco mais a questão, partimos do pressuposto de que os treinamentos serão mais bem sucedidos quando as organizações perceberem a superficialidade de se trabalhar a aprendizagem somente para cumprir 'objetivo-fim'. Em outras palavras, o pragmatismo ${ }^{2}$ é essencial na questão aprendizagem, mas não é possível se pautar pelo imediatismo, que permeia as relações empresa-indivíduo; o resultado deve considerar o processo, que requer etapas e pode demorar um pouco mais para se estabelecer. Indivíduos adultos aprendem de maneira peculiar, que pode diferir da educação formal instituída nos bancos escolares, isso representa afirmar que, muitas vezes, os resultados são comprometidos por se privilegiar as questões cognitivas, sem prévia estruturação das estratégias para que as informações possam ser aplicadas no cotidiano. Outro aspecto a ser considerado é a motivação dos funcionários para o aprendizado; a maneira como o colaborador se ambienta na organização reflete diretamente na apreensão de novos conceitos e/ou estruturas que favoreçam melhores aplicações no âmbito do trabalho.

Primeiro se tratará a respeito da Gestão do Conhecimento, que se relaciona ao repertório do indivíduo: as experiências, valores, informações, capacidade de assumir responsabilidade, tomar

\footnotetext{
2 Pragmatismo vem do grego prágma - significa ação - prática e prático. Desenvolveu-se principalmente nos EUA e GrãBretanha; privilegia a prática e a experiência. O principal
}

decisões coerentes, ter iniciativas e assim por diante. A gestão do conhecimento é o elemento que impulsiona as empresas a capacitar seus funcionários para obtenção de melhores resultados em toda a empresa.

Em seguida será abordada a aprendizagem organizacional. Discutiremos acerca da relação entre aprendizagem organizacional e indivíduos. Será possível às organizações aprenderem sem depender de pessoas? A aprendizagem é o mediador para revisão dos elementos que compõem o repertório do indivíduo. Há uma relação entre aprendizagem e mudança; essa ocorre quando temos mais informações a respeito de determinada questão; quanto mais conhecimento sobre o 'evento', maiores as possibilidades de acertos.

$\mathrm{Na}$ continuidade busca-se compreender como a motivação pode alicerçar um aprendizado. Não basta se motivar para aprender, todavia, sem esse fator torna-se mais difícil a apreensão das informações, uma vez que o 'interesse' integra a sociedade desde os primórdios. "O método cartesiano, tão central para o racionalismo, o cientificismo e o progressismo antigos, deve ser completado e superado por novos métodos sistêmicos, capazes de assumir o holismo, o

representante do pragmatismo foi William James (18421910). Nomes como Charles Sanders Peirce e John Dewey são relevantes nessa corrente.

www.fics.edu.br 296

- 
indeterminismo e o evolucionismo próprios dos sistemas complexos" (MARC HALÉVY, 2010, pág.15).

\section{A Gestão Do Conhecimento}

Ao se referir à educação, sabe-se que não é possível dissociar crescimento social do conceito de educação, em outras palavras, o desenvolvimento da sociedade depende do nível da educação, que favorece a inserção do indivíduo na sociedade, capacitando-o para cumprir sua função social e manter seu status de cidadão consciente acerca de direitos e deveres.

Segundo Carvalho (1973 apud HAYDT, 2010, pág.11) “não há grupo humano, por mais rudimentar que seja sua cultura, que não empreenda esforços de um ou de outro tipo, para educar suas crianças e seus jovens”. Esses esforços chegam às organizações, que cada vez mais promovem treinamentos para seus funcionários.

As empresas enfrentam número crescente de concorrentes, o que faz com que revejam suas práticas e busquem continuamente o diferencial competitivo, que em tese, favorecerá a sobrevivência de suas bases e destaque de seus produtos e serviços. Nessa direção, é possível se deparar com a gestão do conhecimento que pode ser descrita como "o conjunto de processos para criação, disseminação e uso do conhecimento dentro da empresa, com objetivo de desenvolver vantagens competitivas sustentáveis através da criação de valor compartilhada com o mercado" (SCHARF, 2007, pág. 93). Quando se menciona gestão do conhecimento, deve-se esclarecer que o diferencial não se centra no conhecimento em si, mas na maneira como se articula esse conhecimento nas áreas em que se atua. De acordo com Santiago Jr (2007).

O conhecimento é composto por um mix de experiências, valores, informações e insights, o que permite a existência de uma estrutura que torna possivel não apenas a incorporação de novas experiências e informações, mas também a avaliação da relevância delas. O conbecimento tem origem no cérebro das pessoas e, sua presença nas organizações não se restringe apenas ao conteúdo on produção de documento, mas principalmente à aplicação de rotinas, processos e práticas inovadoras on atualizadas (SANTIAGO Jr 2007:20-21).

O conhecimento não pode se limitar ao aspecto quantitativo de acúmulo de informações, mas precisa "libertar o indivíduo" para que ele adquira autonomia com objetivo de lidar com desafios, que surgem cotidianamente. É desse tipo de "aquisição" que os treinamentos carecem por ainda terem como paradigma o desenvolvimento cognitivo e/ou reforço dos aspectos motivacionais. Ora, a estrutura da aprendizagem deve focalizar desenvolvimento do indivíduo, buscando conscientização para a mudança, que deverá permear as práticas diárias, ou seja, teoria e prática devem posicionar-se dinamicamente. Assim, a proposta das Universidades 
Corporativas $^{3}$ é positiva na medida em que prepara o indivíduo para resolver questões efetivas relacionadas ao âmbito funcional do trabalhador.

Santiago Jr (2007, pág. 19) destaca algumas consequências do recurso conhecimento para a sociedade, da qual interessa-nos tratar acerca da primeira que é "a valorização do ser humano, detentor do conhecimento". A tecnologia passa a substituir parcial ou totalmente a mão de obra no processo produtivo. Os produtos requerem cada vez menos recursos materiais e mais recursos intelectuais.

A tecnologia é a propulsora dessa mudança de enfoque: do processo para o indivíduo, que por ser o mediador do conhecimento adquire status prioritário. Nas linhas de produção, o equipamento favorece processos produtivos cada vez mais eficazes, todavia a maximização de sua capacidade depende do olhar atento e do conhecimento metódico do trabalhador. Nas áreas administrativas são necessários colaboradores treinados para que os recursos tecnológicos sejam abarcados integralmente e, para isso, são requeridas habilidades.

\footnotetext{
${ }^{3}$ Segundo Paulo Millet (2003), Universidade Corporativa é uma ação estratégica em prol do desenvolvimento e da educação não apenas de funcionários de alto escalão, mas de todos os colaboradores, dos clientes e dos fornecedores, com o objetivo de atender às estratégias gerenciais de uma organização. Isso é conseguido porque a Universidade Corporativa é um processo em que os colaboradores, em parceria como membros da cadeia de valor, constroem as
}

1.1. Habilidades: Técnicas, Humanas E Conceituais.

Quanto às habilidades, Katz apud Chiavenato (2010, pág.19) estabelece três tipos essenciais: as habilidades técnicas, as habilidades humanas e as habilidades conceituais. As técnicas são mais simples de lidar, pois "envolvem o uso de conhecimento especializado e facilidade na execução de técnicas relacionadas com o trabalho e com os procedimentos de realização". As habilidades humanas, conforme o nome já diz relaciona-se ao trato com pessoas: "Envolvem a capacidade de comunicar, motivar, coordenar, liderar e resolver conflitos pessoais ou grupais". As habilidades conceituais envolvem "a visão da organização, ou da unidade organizacional como todo e a facilidade em trabalhar com ideias e conceitos, teorias e abstrações".

Neste momento, é possível retomar a questão dos treinamentos voltados a capacitar o indivíduo para execução de tarefas/determinada função. Considerando que os treinamentos estão focados em promover habilidade técnica, quais seriam as possibilidades de alcançar melhores

competências individuais e as organizacionais, aumentando a performance da organização. Essa é a principal preocupação da Universidade Corporativa, alinhar o desenvolvimento e a capacitação individuais aos interesses da Organização. Disponível em: $<$ http://www.sectec.go.gov.br/portal/pdf/arq 575 Unive rsidadeAcorporativa.pdf $>$. Acesso em 5 nov.2012. 
resultados, já que as habilidades humanas e conceituais devem integrar o repertório do profissional para domínio de suas atividades? É importante destacar que essas habilidades não são inatas, ou seja, todos têm potencialidade para desenvolvê-las.

DuBrin explicita que as empresas poderiam incentivar a aprendizagem informal por meio de "áreas comuns, como um átrio central ou salões de restaurante que encorajam a interação entre funcionários" (DUBRIN, 2003, pág.56). A aprendizagem informal ${ }^{4}$ relaciona-se a toda situação em que um colega de trabalho auxilia o outro para entendimento de questões relacionadas ao trabalho, como, por exemplo, utilizar mais eficazmente a internet ou o pacote Office e assim por diante. Ainda quanto à aprendizagem informal, DuBrin (2003) expressa que ela pode ser dividida em quatro tipos:

Quadro 1.1 - Os quatro tipos da aprendizagem informal

\begin{tabular}{|c|c|}
\hline Habilidades práticas & $\begin{array}{l}\text { Incluem habilidade e conhecimentos específicos do cargo e competência } \\
\text { técnica. }\end{array}$ \\
\hline Habilidades intrapessoais & $\begin{array}{c}\text { Incluem a solução de problemas, pensamento crítico, limites para a tomada de } \\
\text { risco e a administração do estresse. }\end{array}$ \\
\hline Habilidades interpessoais & $\begin{array}{l}\text { Incluem a comunicação entre pares, habilidades de apresentação e solução de } \\
\text { conflitos. }\end{array}$ \\
\hline Conscientização cultural & $\begin{array}{c}\text { Incluem conscientização profissional, progresso profissional, normas sociais, } \\
\text { compreensão das metas da empresa, padrões de qualidade, expectativas da } \\
\text { companhia e prioridades. }\end{array}$ \\
\hline
\end{tabular}

Fonte do Quadro 1.1 - Habilidades e Dados extraídos do livro Fundamentos do Comportamento Organizacional (DUBRIN 2003, pág. 56).

As nomenclaturas dadas às habilidades por Chiavenato e DuBrin são diferentes, todavia é possível depreender que há intersecção nas ideias, o que parece comprovar que é fundamental ir além das habilidades técnicas e de execução de tarefas.
1.2 - Tríade: Gestão Do Conhecimento/Didática/Treinam ento.

$\mathrm{Na}$ atualidade, é comum visitarmos livrarias que possuem setor específico para Pedagogia/Didática - essas pesquisas têm como

4 DUBRIN, Andrew J. Fundamentos do comportamento organizacional. 3. ed. São Paulo: Cengage Learning, (2003, pág.56). 
objetivo a busca de estratégias e compreensão a respeito de como crianças e adultos aprendem. Nesses mesmos locais, é possível constatar a ausência ou poucas referências voltadas à aprendizagem dos indivíduos nas organizações.

Nos três grupos: crianças, adultos e trabalhadores, sabemos que é fundamental diferir as estratégias; é preciso ir além dos fatores como faixa etária, estrato social, repertório cultural e demais - quando mencionamos aprendizagem que envolve funcionários e organizações, estamos também incluindo questões motivacionais, que serão tratadas adiante.

O treinamento e o desenvolvimento acontecem na opinião de Donadio (1999), “em uma empresa e com adultos. Assim como as estratégias, a didática deve ser coerente com as expectativas e características de pessoas que já conhecem a sua profissão, possuem experiência anterior e razões pragmáticas para participar de um treinamento" (DONADIO, 1999, pág. 28).

O que são os treinamentos e como esses podem propiciar melhor desempenho das tarefas? Atualmente os educadores discutem acerca dos significados do termo 'treinamento', que estão relacionados a capacitar o indivíduo para exercer determinada função, visando também ao aperfeiçoamento do desempenho. $\mathrm{Na}$ opinião de Chiavenato (2009, pág. 37) refere-se a uma "área genérica chamada desenvolvimento, e que é desdobrada em educação e treinamento: o treinamento significa o preparo da pessoa para o cargo, enquanto o propósito da educação é o de preparar a pessoa para o ambiente dentro ou fora de seu trabalho". O treinamento assume, nessa concepção, um caráter restrito e imediato cujo objetivo é o de cumprir determinada função; enquanto que a educação abrange a proposta do treinamento e o preparo para enfrentamento do ambiente interno e externo do trabalho.

Chiavenato (2009, pág.39) explica que muitos treinamentos são elaborados "em função de uma ação sistemática, visando à rápida adaptação da pessoa ao trabalho”, que não deixa de ser válido, entretanto, observa-se que para alcançar, o que os autores chamam de desenvolvimento, é necessário elaborar treinamentos, considerando o diagnóstico inicial das possibilidades de aprendizado do grupo, fazendo uso das potencialidades individuais como elemento agregador de conhecimento, ou seja, a bagagem de cada indivíduo compartilhada propiciará crescimento aos envolvidos - no coletivo as pessoas se completam - gerando o aprendizado organizacional. Continuando o diálogo com Chiavenato (2009, pág.42-43), ele afirma que o treinamento pode envolver quatro tipos de mudanças comportamentais: transmissão de informações, desenvolvimento de habilidades, 
desenvolvimento ou modificação de atitudes e desenvolvimento de conceito.

O primeiro - transmissão de informações - refere-se a "repartir informações entre os treinandos como um corpo integrado de conhecimentos". O segundo - desenvolvimento de habilidades - relaciona-se ao "desempenho do cargo atual ou possíveis ocupações futuras. Tratase de treinamento comumente orientado para o trabalho". No terceiro - desenvolvimento ou modificação de atitudes - considera o treinamento como "uma das principais forças capazes de mudar a atitudes das pessoas e a natureza da sociedade" e no último - desenvolvimento de conceito - o treinamento é "conduzido no sentido de elevar o nível de abstração e conceituação de ideias e de filosofias (...) para que os gerentes posam pensar em termos globais e amplos" (CHIAVENATO, 2009, pág.42-43).

Treinamentos que abarquem esses quatro conteúdos assumirão o status do conceito de 'desenvolvimento', mas ainda é preciso escavar as possibilidades do "como" essas questões podem ser trabalhadas. Os treinamentos devem ser elaborados sob a ótica do formar, conscientizar e desenvolver como elementos prioritários, ou seja, ir além do treinar, pois no cotidiano, os funcionários enfrentam adversidades que exigem tomadas de decisões, as quais requerem profissional dotado de habilidades - além da técnica. Naturalmente, que não é possível ao indivíduo se fragmentar para tomar decisões com caráter essencialmente racional, entretanto, é possível e preciso trabalhar o equilíbrio emocional para tomada de decisões mais conscientes; prioritariamente imparciais - em que se considerem vantagens e desvantagens para a organização e não o simplesmente o próprio interesse. Não se trata de restringir os treinamentos a aspectos motivacionais ou voltados simplesmente a divertir e entreter o funcionário, pois assim que chegar à empresa, ele terá que encarar a realidade organizacional e pode, inclusive, entrar em conflito por comparar as situações experimentadas (bem-estar x situações adversas cotidianas).

Nesse sentido, o treinamento precisa tratar e apontar aplicações práticas para o dia a dia das empresas, que possam promover reflexão e mudança na postura dos indivíduos para melhor desempenho de suas funções, assim, seleção do tema, compartilhamento das informações e situações vivenciadas, escolha criteriosa do material, das estratégias e, principalmente, do orientador do treinamento são fundamentais para essa busca do conhecimento de aprendizagem. De acordo com Senge (2005, pág. 25) "conhecimento e aprendizagem - os processos por meio dos quais as pessoas criam o conhecimento - são sistemas vivos formados por redes e inter-relações 
invisíveis" e essa é a questão que permeará o próximo capítulo.

\section{Aprendizagens Organizacional $\mathrm{X}$} Individual

Ao tratar de aprendizagem organizacional e individual a questão central é saber se as organizações podem ser "desenvolvidas e sustentadas sem 'pessoas de aprendizagem'." (ANTONELLO, 2005, pág.19). Em um primeiro impulso, entende-se que não é possível dissociar aprendizagem organizacional e individual, se considerar que as empresas são representadas por indivíduos e são eles que, de maneira integrada, promovem crescimento; em outras palavras significa dizer que as empresas se utilizam dos recursos individuais para alcançar conhecimentos mais consistentes. De acordo com Argirys e Schön apud Antonello (2005, pág.18): “As organizações não são meramente coleção de indivíduos, embora não existam organizações sem essas coleções". Essa é uma evidência de que indivíduos compõem a organização, mas que há mais elementos para a obtenção do status de organização - não se trata, portanto, de coletividade, mas de processos e sistemas e stakeholders (internos e externos) e etc., que compõem e agem nas organizações para que ocorram mudanças e consequentemente o aprendizado. Quanto a esse fenômeno, Antonello (2005, p.18) afirma que "a literatura existente promove uma relação forte entre aprender e mudar, e alguns autores comentam que as duas práticas são sinônimas".

Certamente, os conceitos de aprender e mudar estão imbricados, entretanto, é reducionismo classificá-los como práticas sinônimas, isso implicaria afirmar similaridade entre os significados de aprender e mudar. Nessa direção, é mais interessante expressar, conforme Antonello, essa forte relação. Observa-se estreita relação entre aprendizagem e situações, que requerem uma resposta a determinados problemas. A solução de problemas requer o compartilhamento dos conhecimentos dos envolvidos, o que conduz à reflexão de que a troca entre indivíduos é um elemento facilitador para o aprendizado. Por ser de ordem social, três elementos - indivíduo, coletividade e situaçãoproblema - devem ser considerados no aprendizado.

\section{1 - Aprendizado Organizacional: As Implicações}

$\mathrm{O}$ aprendizado organizacional para o colaborador tem um fim específico: eles sabem que aquele treinamento é uma maneira de realizar melhor suas atividades e, muitas vezes, consideram que pode ser uma forma de alcançar promoção. 
Apesar disso, não basta estar cônscio sobre essa situação, o indivíduo precisa estar satisfeito com seu trabalho, pois do contrário não demonstrará interesse pelo treinamento, podendo, inclusive, atrapalhar os colegas ao propagar aspectos negativos devido ao seu conflito interior, essa questão relaciona-se à percepção, que é como recebemos e interpretamos o mundo a nossa volta. Robbins define percepção como "um processo pelo qual indivíduos organizam e interpretam suas impressões sensoriais a fim de dar sentido ao seu ambiente”. (ROBBINS, 1998, pág.62).

DuBrin (2003) explica que "As percepções no trabalho são importantes (...) empregados que encaram seu cargo como desafiador e interessante apresentam alto grau de satisfação e motivação no trabalho (DUBRIN, 2003, pág.58)". Outro ponto a ser discutido é a leitura de mundo ${ }^{5}$, que difere entre os indivíduos, não apenas por sua especialização, mas pela trajetória própria de cada um, assim, ao serem propostos treinamentos, torna-se fundamental considerar que cada pessoa é singular, portanto não veem, não percebem, não compreendem, não apreendem de maneira igual essa é uma questão que requer um olhar mais atento por parte daqueles que se propõem a partilhar conhecimentos; há muitos ruídos na comunicação.

\footnotetext{
${ }^{5}$ Conceito de Paulo Freire, educador brasileiro. De maneira simplificada, podemos entender leitura de mundo como o nosso repertório cultural, que inclui palavras, mas que depende de outras relações. "A leitura de mundo precede a leitura da palavra,
}

Ademais, a falta de valorização cultural atribuída pela nossa sociedade ao saber contribui para o não aprendizado. Também a importância/satisfação que o indivíduo tem em relação ao trabalho que está executando; como ele age, percebe e reage ao entorno. Nesse sentido, o envolvimento dos funcionários nos treinamentos depende, conforme já situado, da ligação que ele estabelece com a empresa, da maneira como ele se posiciona nessa, no valor que atribui ao seu trabalho, em como sente motivado e capaz de promover mudanças, considerando o nível de sua autoestima entre outros itens. Por essas razões, é possível inferir que a aprendizagem é complexa; dependente de uma série de fatores. Teoricamente, é fundamental realizar diagnósticos individuais, mas no aspecto prático não é fácil realizar essa constatação. São discutíveis, no entanto, as condições que as organizações podem propiciar em prol da busca pelo seu diferencial competitivo, que é o capital humano preparado.

\section{2 - Autonomia Como Estratégia De Aprendizado}

Outro aspecto comentado anteriormente e que, agora, assume relevância é o conceito de 'autonomia'. Pedro Demo (2011, pág.10), afirma

daí que a leitura desta não possa prescindir da leitura daquele. Linguagem e realidade se prendem dinamicamente". (FREIRE, 2011, pág.19) 
que a característica emancipatória da educação "exige a pesquisa como seu método formativo, pela razão principal de que somente um ambiente de sujeitos gera sujeitos". É importante esclarecer que tais afirmações se referem a um ambiente de aprendizagem formal: a escola, mas consideramos que esse conceito possa ser aplicado nas organizações e nos respectivos treinamentos, pois em certa medida não se trata apenas de executar bem a tarefa; é preciso, apropriando-nos das palavras de Demo (2010, pág.10) "trabalhar o trajeto coincidente entre pesquisa e educação":

Quadro-Síntese 2.1 - Trajeto coincidente pesquisa e educação.

\begin{tabular}{|c|c|c|}
\hline Pontos em comum & Objetivo da Pesquisa & Objetivo da Educação \\
\hline Ação contra a ignorância & Conhecer - agir na base do sabe pensar. & $\begin{array}{l}\text { Ter consciência crítica - marca essencial de } \\
\text { quem sabe e sabe da realidade. }\end{array}$ \\
\hline $\begin{array}{l}\text { Valorização } \\
\text { questionamento }\end{array}$ & $\begin{array}{l}\text { Alimentar-se de dúvidas, hipóteses: } \\
\text { alternativas de explicação e superação } \\
\text { constante de paradigmas. }\end{array}$ & Alimentar o aprender a aprender. \\
\hline $\begin{array}{l}\text { Dedicação ao processo } \\
\text { reconstrutivo }\end{array}$ & $\begin{array}{l}\text { Manter a inovação como processo } \\
\text { permanente }\end{array}$ & $\begin{array}{l}\text { Alicerçar história de sujeitos para sujeitos, } \\
\text { usando o conhecimento inovador como } \\
\text { instrumento. }\end{array}$ \\
\hline $\begin{array}{l}\text { Confluência entre teoria e } \\
\text { prática. }\end{array}$ & $\begin{array}{l}\text { Buscar na prática a renovação da teoria } \\
\text { e na teoria a renovação da prática }\end{array}$ & $\begin{array}{l}\text { Encontrar no conhecimento a alavanca crucial } \\
\text { da intervenção inovadora, agregando } \\
\text { compromisso ético. }\end{array}$ \\
\hline $\begin{array}{l}\text { Oposição à condição de } \\
\text { objeto. }\end{array}$ & $\begin{array}{l}\text { Usar a transmissão de conhecimento } \\
\text { como ponto de partida e se realiza em } \\
\text { sua reconstrução permanente. }\end{array}$ & $\begin{array}{l}\text { Ultrapassar o mero ensino, instrução, } \\
\text { treinamento, domesticação. }\end{array}$ \\
\hline $\begin{array}{l}\text { Oposição a procedimentos } \\
\text { manipulativos. }\end{array}$ & $\begin{array}{l}\text { Supor ambiente de liberdade de } \\
\text { expressão, crítica e criatividade. }\end{array}$ & $\begin{array}{l}\text { Exigir a relação pedagógica interativa e ética, } \\
\text { marcada pela qualidade formativa. }\end{array}$ \\
\hline Condenação de cópias. & $\begin{array}{l}\text { Privilegiar como método } \mathrm{o} \\
\text { questionamento sistemático crítico e } \\
\text { criativo }\end{array}$ & $\begin{array}{l}\text { Reagir contra o ensino copiado, privilegiando o } \\
\text { saber pensar e o aprender a aprender. }\end{array}$ \\
\hline
\end{tabular}

Fonte: Educar pela Pesquisa. (Demo 2010, pág. 10-11). Adaptação da autora 2014.

Considerando altos investimentos que empresas têm aplicado na gestão do conhecimento, torna-se fundamental imbricar por esse trajeto pesquisa/educação, buscando formação de um profissional integral, pois os indivíduos precisam de apoio para alcançar a autonomia, que, em última instância, representa saber lidar com situações adversas que surgem e que se alternam; não sendo possível conhecer um único caminho, aplicando, frequentemente, a 
mesma fórmula para situações que já são diferentes e requerem utilização de novas estratégias e decisões mais adequadas à ocorrência do momento; de maneira simplificada: o contexto determina os próximos passos; a nossa única certeza é a da mudança.

Diferentes situações-problema são oportunidades de crescimento e aprendizado tanto para o indivíduo como para a organização; apesar de ser senso comum mencionar sobre a resistência que há em torno das mudanças e, retornando à Antonello: mudança e aprendizado.

Aprendizado que é social e que se constitui por meio de relações de alteridade, que propiciam crescimento individual e coletivo, haja vista a ampliação de repertório que se processa na medida em que conseguimos penetrar no mundo do outro e compreender seu ponto de vista, ademais essa nova perspectiva, pela qual somos tocados, ampliará as possibilidades de solução, trazendonos um diagnóstico mais preciso face às solicitações organizacionais.

\section{3 - Andragogia: O Tratamento Do Indivíduo Adulto.}

A Pedagogia costuma ser relacionada primeiramente com aprendizagem de crianças, mas sabemos que essa área também abrange o público adulto. O conceito de Andragogia é específico para o adulto e, apesar de ser antigo, ainda carece de pesquisadores que detenham o olhar sobre a questão. Vogt e Alves (2005) no Artigo Revisão Teórica sobre a Educação de Jovens e Adultos para uma aproximação com a pedagogia traçam um breve histórico sobre o assunto:

O termo andragogia foi formulado originalmente por Alexander Kapp, professor alemão, em 1833; caiu em desuso e reapareceu em 1921, no relatório de Rosenstok, sinalizando que a educação de adulto requer professores, métodos e filosofia diferenciados. Eduard Lindeman, em 1927, adoton o termo de Rosenstock e usou-o poucas vezes nos Estados Unidos. O vocábulo andragogia foi utilizado amplamente, desde a década de 60, na França, Yugoslávia e Holanda para se referir à disciplina que estuda o processo da instrução de adulto ou a ciência da educação de adulto. (VOGT e ALVES, 2005).

A UNESCO ${ }^{6}$, em 1949 realiza a primeira conferência sobre Educação de Adultos e tem como objetivo minimizar os índices de

educação de adultos, que consagrou o compromisso dos governos em promover a educação dos adultos como parte integrante do sistema educacional, numa perspectiva de aprendizagem ao longo da vida. (UNESCO, 2010, pág.12)

\footnotetext{
${ }^{6}$ Desde a primeira conferência sobre Educação de Adultos em 1949, a UNESCO tem trabalhado com os Estados-membros para assegurar que os adultos exerçam o direito fundamental à Educação. Em 1976, a Conferência Geral da UNESCO aprovou a Recomendação de Nairóbi para o desenvolvimento da
} 
analfabetismo. Em 2009, na sexta conferência, a prioridade se deu em torno da mesma questão e o primeiro compromisso estabelecido foi desenvolver "uma oferta de alfabetização que conduza à obtenção de conhecimentos, capacidades e competências funcionais e sustentáveis pelos participantes, empoderando-os para que continuem a aprender ao longo da vida" (UNESCO, 2011, pág. 4).

Não basta, portanto, alfabetizar os indivíduos é necessário dar condições para que possam, de maneira autônoma, continuar aprendendo. Esse conceito vem ao encontro das ideias expressas no trabalho: a de que é preciso 'empoderar' os indivíduos para que possam tomar decisões coerentes com bases em dados palpáveis, concretos, seguindo critérios, deixando um pouco de lado o velho paradigma das tentativas: erros e acertos. A Andragogia é a ciência que se preocupa com o aprendizado do adulto, buscando pensar estratégias que o auxiliem a alcançar esse saber emancipatório de que se tem tratado com mais ênfase nos últimos anos. Neste sentido, a Didática precisa ser diferenciada e contemplar os aspectos do indivíduo maduro. Malcolm Knowles aponta cinco premissas, a saber:

\section{Quadro 2.2 - Diferenciação entre crianças e adultos}

\begin{tabular}{|l|l|}
\hline Autoconceito & Ser de personalidade dependente para um autodirigido. \\
\hline Reservatório de experiência & Acumula e se transforma em um recurso crescente para aprender. \\
\hline Prontidão a aprender & $\begin{array}{l}\text { Torna-se orientada, cada vez mais, às tarefas de desenvolvimento de seus papéis } \\
\text { sociais. }\end{array}$ \\
\hline Perspectiva de tempo & $\begin{array}{l}\text { Muda de uma procrastinação do conhecimento à imediata aplicação e orientação, } \\
\text { sendo que a orientação da aprendizagem desloca-se de uma aprendizagem } \\
\text { centrada nas disciplinas a uma centrada no problema. }\end{array}$ \\
\hline Motivação & É interna no indivíduo amadurecido. \\
\hline
\end{tabular}

Fonte: Knowles (1980, pág. 44-45).

Gadotti (2003, pág. 39) afirma que “A Andragogia tem ensinado que a realidade do aluno adulto é diferente da realidade da criança, mas ainda não incorporamos esse princípio em nossas metodologias (GADOT'TI, 2003, pág.39). O indivíduo adulto sofre da síndrome do imediatismo; precisa aplicar o que aprende - ver prontamente os resultados, principalmente ao tratarmos de capacitação profissional e que possam ajudá-lo na manutenção das necessidades primárias e secundárias, conceito mencionado por 
Maslow ${ }^{7}$. O aprendizado passa a ser uma moeda de troca "mercari": utilidade e retorno.

Donadio (1999, pág.14), pesquisador e especialista em treinamentos ao se referir às pesquisas de Knowles diz que é preciso considerar: como a adulto vê a si próprio; sua experiência anterior; perspectiva temporal (aplicações em curto prazo) e necessidade de aprender com base em necessidades reais e concretas. Para que o treinamento alcance seus reais objetivos é necessário considerar componentes como visão de mundo, objetivos, estratégias, didática, conteúdos recursos instrucionais e avaliação (DONADIO, 1999, pág.74), além da mudança do enfoque tradicional para o Andragógico:

\section{Quadro 2.3 - Componentes: visão tradicional x andragógica}

\begin{tabular}{|c|c|c|}
\hline Componentes & Tradicional & Andragógico \\
\hline Visão do mundo & $\begin{array}{l}\text { A pessoa é um ser em transformação. } \\
\text { Difundir a instrução, transmitir } \\
\text { conhecimentos e sistematizá-los. }\end{array}$ & $\begin{array}{l}\text { A pessoa é o sujeito do seu aprendizado; a educação é força de } \\
\text { mudança e libertação - coloca a reflexão sobre seu tempo e } \\
\text { espaço. Educador e educando vivem uma relação afetiva. }\end{array}$ \\
\hline Objetivos & $\begin{array}{l}\text { Nos treinamentos, superar } \\
\text { insuficiências de desempenho; no } \\
\text { desenvolvimento, criar condições de } \\
\text { maior eficácia da pessoa ou estratégia da } \\
\text { empresa. }\end{array}$ & $\begin{array}{l}\text { Definidos a partir das oportunidades criadas pelos conflitos entre } \\
\text { as turbulências ambientais e forças de manutenção da empresa. } \\
\text { Devem gerar assimetrias e desequilíbrios hierarquizados em } \\
\text { vetores. }\end{array}$ \\
\hline Estratégias & $\begin{array}{l}\text { Frente às propostas do T\&D definem- } \\
\text { se os conhecimentos, atitudes e } \\
\text { habilidades desejáveis e elaboram-se } \\
\text { programas para ensiná-los. }\end{array}$ & $\begin{array}{l}\text { Parte do equilíbrio dinâmico das forças de organização, } \\
\text { desorganização das pessoas maduras. Considera uma necessidade } \\
\text { real do participante, dinamiza e eleva para uma problematização } \\
\text { mais complexa. }\end{array}$ \\
\hline Didática & $\begin{array}{l}\text { Há recordação da lição anterior, } \\
\text { apresentação do novo conhecimento, } \\
\text { compara-se com o anterior, generaliza- } \\
\text { se para novas situações; aplica-se em } \\
\text { exercícios, avalia-se o aprendizado. }\end{array}$ & $\begin{array}{l}\text { Privilegia os grupos operativos como campo de processos } \\
\text { interpessoais de troca de conceitos e referências. Os conflitos e } \\
\text { acomodações para apropriação da nova realidade conduzem a } \\
\text { conceitos, referências e operações mais complexas. }\end{array}$ \\
\hline Conteúdos & $\begin{array}{l}\text { Tanto no treinamento como no } \\
\text { desenvolvimento, decorrem } \text { dos }\end{array}$ & $\begin{array}{l}\text { Decorrem dos objetivos, estratégias, e são criados pela própria } \\
\text { didática através da sinergia dos conhecimentos anteriores dos }\end{array}$ \\
\hline
\end{tabular}

7 Segundo Abraham Maslow as necessidades dos seres humanos estão colocadas em categorias. São elas: primárias
- necessidades fisiológicas e de segurança. Secundárias necessidades sociais, de estima e de autorrealização. 


\begin{tabular}{|c|c|c|}
\hline & $\begin{array}{l}\text { objetivos e estratégias e devem adequar- } \\
\text { se à didática. }\end{array}$ & $\begin{array}{l}\text { participantes e informações do coordenador em processos de } \\
\text { síncrese, análise e síntese. }\end{array}$ \\
\hline $\begin{array}{l}\text { Recursos } \\
\text { Instrucionais }\end{array}$ & $\begin{array}{l}\text { São utilizados trabalhos em grupo; } \\
\text { estudos de caso, instrução programada; } \\
\text { audiovisuais, apostilas, livros. } \\
\text { Geralmente com adequação e } \\
\text { coerência. }\end{array}$ & $\begin{array}{l}\text { Todos utilizados tradicionalmente: mais dramatizações, jogos e } \\
\text { simulações. Cada um deles deve apoiar os vetores estratégicos, } \\
\text { dinâmicos, dinâmica ou interações didáticas. }\end{array}$ \\
\hline Avaliação & $\begin{array}{l}\text { Afere-se a reação do participante ao } \\
\text { final do treinamento, a melhoria do seu } \\
\text { desempenho no trabalho e o impacto } \\
\text { nos negócios da empresa. }\end{array}$ & $\begin{array}{l}\text { O adulto é capaz de ele mesmo avaliar seu aprendizado e } \\
\text { significância do T\&D para ele. }\end{array}$ \\
\hline
\end{tabular}

Fonte: Extraído na íntegra do livro T\&D: ensinando as empresas a aprender (1999, pág. 74).

Em síntese, a mudança de ênfase ao tratar de cada um desses elementos pode ser o diferencial para um melhor aprendizado.

\section{4 - Possibilidades De Ensino Ao Aluno Adulto: A Plasticidade Cerebral}

O homem é um ser sócio-histórico permeado por construções e desconstruções. O adulto não é uma folha em branco $^{8}$, ele já vem com uma bagagem, que se por um lado é base para dar significado ao aprendizado, por outro, torna-se limitante, pois crenças, condicionamentos impedem a revisão de ações enraizadas, restringindo seu crescimento.

\footnotetext{
${ }^{8}$ Comenius em seu livro Didática Magna comenta sobre a importância de iniciar a Educação desde cedo, quando,
}

Questões como inatismo já são ultrapassadas bem como a de que adultos têm mais dificuldade para o aprendizado. As exigências contemporâneas requerem revisão, conforme podemos compreender com Makeliny Oliveira (2009: pág.65 e 66). O primeiro é o da inteligência, que durante décadas se acreditou ser imutável e mensurável, ou seja, o ser já nascia com um nível de inteligência determinado, em outras palavras, acreditava-se que a inteligência era um dom. O segundo conceito é o de criatividade, que era considerada como ferramenta de alguns privilegiados. O terceiro é o de memória, que era tida como um receptáculo cujo objetivo era acumular informações.

segundo ele a mente ainda não foi ocupada, principalmente por preconceitos e valores mundanos (COMENIUS, 1621 1657, pág. 35). 
Partindo do pressuposto de que somos seres sociais e que aprendemos em interação com os outros, devemos considerar o conceito de plasticidade cerebral, já que o homem está em constante aprendizado, independentemente de sua idade:

\begin{abstract}
Atualmente com o avanço dos estudos dos neurocientistas, descobriu-se que o conceito de inteligência como algo imutável não condiz com a realidade bumana. Dessa forma, esse conceito foi reformulado, pois se acredita que é na vivência que o homem vai se constituindo e se transformando, podendo mudar não só o meio sociocultural em que vive, mas também o biológico (plasticidade cerebral). Assim, a inteligência é compreendida atualmente como um processo dinâmico, construído na interação do sujeito com a cultura, e pode ser desenvolvida independentemente da idade da pessoa. (NOGUEIRA, 2009, pág. 65).
\end{abstract}

O aprendizado é um aspecto potencial do indivíduo, fazendo alusão ao sábio Heráclito de Éfeso, pai da dialética, não entramos duas vezes no mesmo rio. Isso representa afirmar que estamos em constante mudança e o aprendizado está relacionado a essa questão. Resta-nos entender como a motivação interfere nesse caminho, que é o aspecto a ser abordada no capítulo 3.

\section{Motivação}

$\mathrm{Na}$ etimologia do termo motivo (latim motivus ${ }^{9}$ ) encontramos ideia de movimento, móvel.

\footnotetext{
${ }^{9}$ Motivo (séc.XVIII) que pode fazer mover, que causa ou determina alguma coisa, causa, razão, fim, intuito. Motivação surge em 1899 e o termo motivador em 1844.
}

Não está explícito movimento de dentro para fora ou ao contrário, mas é possível inferir pelo termo que mover pode ocorrer nos dois sentidos. Macedo (2006, pág.92) conceitua a etimologia de motivação: “... as palavras motivo e emoção compartilham a mesma raiz do latim: movere, isto é, mover. Assim são as emoções que impulsionam as pessoas em direção a suas metas e que também influenciam a sua maneira de perceber os fatos".

Robbins (2001, pág. 108) e Chiavenato (2001, pág. 477) conceituam motivação de forma bastante semelhante. O primeiro define motivação organizacional como "vontade de empregar altos níveis de esforço em direção a metas organizacionais, condicionada pela capacidade do esforço de satisfazer alguma necessidade do indivíduo". O segundo vê motivação como "o desejo de exercer altos níveis de esforço em direção a determinados objetivos organizacionais, condicionados pela capacidade de satisfazer algumas necessidades individuais”. Por sua vez, DuBrin (2003, pág. 110) afirma que é "o processo pelo qual o comportamento é mobilizado e sustentado no interesse da realização das metas organizacionais. Sabemos que uma pessoa está motivada quando ela realmente despende esforço para alcance da meta". Refletindo sobre as colocações destes teóricos, pode-se extrair

CUNHA, Antonio Geraldo de. Dicionário Etimológico Nova Fronteira da Língua Portuguesa. Rio de Janeiro: Nova Fronteira, 1991. 
palavras-chave como recompensa e interesse associadas ao conceito de motivação.

\section{1 - Motivação Para Aprendizagem: Teorias E Métodos}

Andrew DuBrin (2003) disserta sobre dois métodos de aprendizagem (a modelagem e a configuração), que auxiliam na aquisição de habilidades complicadas. A modelagem diz respeito à imitação. O termo 'imitação' é empregado no sentido de aprender pela observação do outro, no desempenho das atividades. $\mathrm{O}$ autor esclarece que "a modelagem muitas vezes traz à tona comportamentos que as pessoas não pareciam ter anteriormente em seu repertório” (DUBRIN, 2003, pág. 54).

Bandura em seus estudos sobre os conceitos sociais de aprendizagem explicita três aspectos centrais da teoria de aprendizagem. "O primeiro é a ideia de que pessoas podem aprender através da observação. Em seguida é a ideia de que estados mentais internos são uma parte essencial desse processo. Finalmente, esta teoria reconhece que só porque algo foi aprendido, isso não significa que ele irá resultar em uma mudança de comportamento" 10 . Outro processo é a

\footnotetext{
10 First is the idea that people can learn through observation. Next is the idea that internal mental states are an essential part of this process. Finally, this theory recognizes that just because something has been learned, it does not mean that it will result in a change in behavior. Disponível em: <
}

configuração, que ele classifica como formatação por se tratar da "aprendizagem por meio do reforço ou premiação de pequenos passos para se chegar até o final ou ao comportamento desejado" (DUBRIN, 2003, pág.55).

A configuração pode ser mais bem compreendida por meio da teoria Behaviorista, que trata a respeito do comportamento como reflexo da interação entre sujeito e ambiente. Ações e respostas estão ligadas ao sujeito enquanto os estímulos fazem parte do ambiente. O ambiente promove estímulos no sujeito que ao ser recompensado sente-se predisposto a realizar mais e melhor suas atividades. Essa teoria gerou "controvérsias devido ao seu caráter mecanicista" (ARANHA, 2008, pág. 257).

Apesar do caráter mecanicista mencionado por Aranha (ANO), podemos observar diversas empresas que procuram reforçar o desempenho dos seus funcionários por meio de premiações diversas, inclusive hospedagens, milhagens, eventos para os filhos dos funcionários e assim por diante. Algumas adotam, mesmo se deparando com a legislação brasileira, sistemas de remuneração flexível ${ }^{11}$.

\footnotetext{
http://psychology.about.com/od/developmentalpsychology/a/sociallearn ing.htm>. Acesso em 27 out.2012

${ }^{11}$ Para saber mais, acesse

<http://www.lcsantos.pro.br/arquivos/A_Remuneracao20 062008-114207.pdf>.
} 
Para maior compreensão do aspecto comportamento/reforço, temos a teoria de expectativa formulada por Victor Vroom em 1964 que, em síntese, representa a questão do valor atribuído à recompensa e como essa determina sua eficácia:

(...) a teoria da expectativa diz que um empregado estará motivado a empregar um alto nivel de esforço quando acreditar que o esforço levará a uma boa avaliação de desempenho; que uma boa avaliação de desempenho levará a recompensas organizacionais como um bônus, um aumento de salário ou uma promoção; e que as recompensas satisfarão as metas pessoais do empregado. A teoria, portanto, enforca três relações: esforço-desempenho e recompensas-metas pessoais. (ROBBINS, 1998, pág.118).

Com base no exposto, parece-nos haver uma tendência a produção/retorno. Cabe-nos apontar também que essa é uma questão subjetiva, ao considerarmos que premiação adequada para determinado indivíduo, pode ser insignificante para outro; a exata medida depende da valoração atribuída por cada um de nós.

Essa questão já havia sido levantada no século XVIII pelo alemão Johann F.Herbart, precursor da psicologia experimental aplicada à pedagogia, que insatisfeito com a precária assimilação dos conteúdos ensinados na escola, elaborou a teoria dos interesses. "Herbart atribuía a causa à aplicação inadequada dos métodos, incapazes de relacionar os conhecimentos adquiridos com a experiência do indivíduo, o que resulta em material inutilmente memorizado e logo esquecido" (ARANHA, 2006, pág. 212). Herbart estava se referindo ao aprendizado infantil, entretanto ele já percebia no comportamento dos pequeninos a necessidade de associar aprendizado a retorno.

A motivação é um assunto que sempre instigou pesquisas. Os teóricos dividem-na em teorias do conteúdo e teorias de processo. $\mathrm{Na}$ primeira, conta-se com a teoria da hierarquia das necessidades, de Maslow; Teoria dos Motivos humanos, de McClelland; Teoria dos dois fatores, de Herzberg (MACEDO, 2006, pág.92-95). Chiavenato (2010, pág.482) inclui a teoria ERC de Alderfer e Robbins (1998, pág.110) faz menção à Teoria X e Teoria Y de Douglas Mc. Gregor.

$\mathrm{Na}$ teoria de processo temos estabelecimento de objetivos, de Locke (ANO), Teoria da expectativa, de Vroom (já mencionada), Teoria da equidade, de Adams. (MACEDO, 2006, pág. 96-99). Chiavenato (2010, pág.486) e Robbins (1998, pág.116) dissertam a respeito da Teoria do Reforço, que são baseadas na velha lei do efeito de Thorndyke. Todas essas teorias contribuem para compreender melhor o homem, seu comportamento; seja no aspecto da produtividade, rotatividade e demais variáveis; elas diferem na força da previsão, pois são dependentes das circunstâncias que envolvem os indivíduos. 
Muito se tem dialogado acerca das teorias e aplicações, contudo, sabemos que ainda estamos aquém do entendimento integral do indivíduo e das organizações, principalmente, ao buscarmos o significado maior expresso na nossa epígrafe: a busca dos novos métodos sistêmicos, capazes de assumir o holismo, o indeterminismo e o evolucionismo próprios dos sistemas complexos.

\section{Metodologia}

Em virtude da subjetividade do tema escolhido e da dificuldade em mensurar as análises de maneira pontual, foi feita a opção pela metodologia qualitativa analítica de caráter documental e com base em bibliografias, por meio de análise de dados secundários, provenientes de textos científicos e bibliografias no intuito de recuperar o modelo conceitual. É importante destacar que a pesquisa contemplou um pequeno universo diante da complexidade da questão e dos estudos realizados.

\section{Considerações Finais}

Por meio de investigação das publicações de teóricos, pudemos concluir que, de fato, as empresas estão bastante preocupadas com o capital intelectual de seus colaboradores para manter seus acervos de informações cujo objetivo é alcançar excelência na fabricação de produtos e prestação de serviços.

Propiciar treinamentos adequados ao público adulto é complexo e depende de uma série de contingências. $O$ adulto já possui paradigmas enraizados, difíceis de serem revistos, ele já vem com uma série de informações, fruto de sua trajetória, que ora atrapalham esse aprendizado, ora favorecem para entendimento ampliado. É fundamental entender as diferenças de fases e expandir o conceito pedagógico, considerando a Andragogia como ciência que favorece atualização dos setores de recursos humanos, quando tratam os indivíduos, considerando a maturação como elemento favorecedor desse aprendizado.

As organizações aprendem e conseguem ampliar suas perspectivas, a partir do momento em que contam com indivíduos, que estejam motivados a aprender e a compartilhar desse aprendizado com os demais. Isso considerando que o aprendizado não ocorre somente nos treinamentos agendados, mas é cotidiana e se dá nos mais inesperados momentos, no contato de um indivíduo com o outro.

Há um provérbio antigo e bastante conhecido: "Não basta dar o peixe, é preciso ensinar a pescar." Os treinamentos, necessariamente, devem dar condições ao indivíduo para construir seu próprio percurso. $\mathrm{O}$ 
aprendizado precisa ser um sinalizador do caminho, afinal, não basta saber, mas compreender o que fazer com esse saber, portanto, uma palavra fundamental é autonomia.

Outro aspecto fundamental é a motivação. Várias teorias foram elaboradas acerca da questão e são importantíssimas para compreensão do comportamento. Entretanto, parece-nos que há uma ampla lacuna de subjetividade, ligada ao indivíduo, a qual nos faz perceber que o grande diferencial mesmo é a capacidade de captar e perceber o outro, presente em cada orientador.

Referências Bibliograficas

ANDRADE, A.L. et al. Pensamento sistêmico: o desafio da mudança sustentada nas organizações e na sociedade. Porto Alegre: Bookman, 2006.

ANTONELLO, Claudia.S; RUAS, Roberto; BOFF, Luiz Henrique. Aprendizagem organizacional e comportamental. Porto Alegre: Bookman, 2005.

ARANHA, Maria Lúcia de Arruda. História da Educação e da Pedagogia: geral e Brasil. 3. ed.São Paulo, Moderna: 2008.

CHIAVENATO, I Treinamento e desenvolvimento de recursos humanos: como incrementar talentos na empresa. 7 ed. Barueri, SP: ed. Manole, 2010.

\section{CHIAVENATO I. Administração nos novos} tempos. 2. ed. Rio de janeiro: Elsevier, 2010.

DEMO, Pedro. Educar pela pesquisa. 9. ed. Campinas, SP: Autores Associados, 2011.

DONADIO, M. Treinamento \& Desenvolvimento total: ensinando as empresas a aprender. 2. ed. Rio de Janeiro: QualityMark, 1999.

DUBRIN, Andrew J. Fundamentos do comportamento organizacional. 3. ed. São Paulo: Cengage Learning, 2003.

GADOTTI, Moacir; ROMÃO José E. (Org.) Educação de Jovens e Adultos: teoria, prática e proposta. 6. ed. São Paulo: Cortez, 2003.

HAYDT. Regina Célia Cazaux. Curso de didática geral. 7. ed. São Paulo: Ática, 2001.

LOPES, I. (org.); Trindade A.B.; Cadinha M.A. Pedagogia empresarial: formas e contextos de atuação. 3 ed. Rio de Janeiro: Wak Ed, 2009.

MACÊDO, I.I de. et al. Aspectos comportamentais da gestão de pessoas. $7 \mathrm{ed}$. Rio de Janeiro: FGV, 2006

NOGUEIRA, Makeliny Oliveira Gomes. Aprendizagem do aluno adulto: implicações 
para a prática docente no ensino superior. Curitiba: Ibpex, 2009.

PIMENTA, Selma Garrido. (Org.). Saberes pedagógicos e atividade docente. São Paulo, Cortez, 2009.

PIMENTA, Selma Garrido; GHEDIN, Evandro. (Org.). Professor Reflexivo no Brasil: gênese e crítica de um conceito. 4.ed. São Paulo: Cortez, 2006.

ROBBINS, S. Comportamento

Organizacional. Rio de Janeiro: LTC, 1999.

SANTIAGO JR. J.R.S. Capital intelectual: o grande desafio das organizações. São Paulo: Novatec, 2007.

SCHARF, E.R. Gestão do conhecimento aplicada ao marketing: como usar conhecimento e ações orientadas para o mercado no desenvolvimento de vantagens competitivas sustentáveis. Florianópolis: Visual Books, 2007.

SCHÖN, Donald. Educando o Profissional Reflexivo: um novo design para o ensino e a aprendizagem. Porto alegre: Artmed, 2000.

SENGE. P. et. al. Escolas que aprendem: um guia da quinta disciplina para educadores, pais e todos que se interessam pela educação. Porto Algre: Artmed, 2005.
ZABALA, Antoni. A Prática Educativa: como ensinar. Porto Alegre: Artmed, 1998.

Referencias Eletrônicas

SANTOS L.C. et. al. A remuneração flexível e a competitividade. Disponível em: $<$ http://www.lcsantos.pro.br/arquivos/A Remu neracao20062008-114207.pdf>. Acesso em 3 nov.2012.

UNESCO. Disponível em: < http://unesdoc. unesco.org/images/0018/001886/188644por.pdf >. Acesso em 21 set.2011.

UNESCO. Disponível em: < $\underline{\text { http://unesdoc. }}$ unesco.org/images/0019/001910/191054por.pdf >. Acesso em 21 set.2011.

VOGT, M.S.L, ALVES, E.D. Revisão teórica sobre a educação de adultos para uma aproximação com a Andragogia. Disponível em: $<$ http://coralx.ufsm.br/revce/revce/2005/02/a 12.htm>. Acesso em 21 set.2011.

UNIVERSIDADE CORPORATIVA DO ESTADO DE GOIÁS. < http://www.sectec. go.gov.br/portal/pdf/arq 575 UniversidadeAco rporativa.pdf $>$ Acesso em 5 nov.2012. 